\title{
Internacionalização da Educação Superior: a questão da mobilidade discente na Universidade Federal de Mato Grosso do Sul, UFMS (2011-2017)
} Internationalization of Higher Education: the issue of student mobility at the Federal University of Mato Grosso do Sul, UFMS (2011-2017)

Internacionalización de la Educación Superior: la cuestión de la movilidad estudiantil en la Universidad Federal de Mato Grosso do Sul, UFMS (2011-2017)

Silvia Helena Andrade de Brito ${ }^{1}$

Margarita Victoria Rodríguez ${ }^{1}$

Carina Elisabeth Maciel $^{1}$

DOI: http://dx.doi.org/10.20435/serie-estudos.v0i0.1380

\begin{abstract}
Resumo: Considerado um dos processos fundamentais para a Educação Superior na atualidade, a internacionalização abrange a participação em projetos conjuntos de pesquisa; a conformação de currículos interinstitucionais; a publicação em veículos internacionais etc. Entre suas várias facetas, destaca-se a mobilidade discente, envolvendo graduação e pós-graduação. Este é o objeto deste artigo, que discute a mobilidade discente internacional na Universidade Federal de Mato Grosso do Sul (UFMS), entre 2011 e 2017. Para tal, foi priorizado o estudo do Programa Ciência sem Fronteiras e do Programa de Doutorado-Sanduíche no Exterior, que contaram com financiamento da Capes e do CNPq. O objetivo geral do artigo é analisar como se deu a implementação desses programas na UFMS e alguns impactos das políticas ali desenvolvidas. Os dados foram coletados nos relatórios de gestão da UFMS, Capes e CNPq e na produção que analisa a mobilidade discente internacional no Brasil. Como conclusões, destaque-se a forma como tais políticas educacionais induziram o fazer científico na UFMS, ao privilegiar determinadas áreas do conhecimento e países de destino. Ao mesmo tempo que tais políticas deram forma à institucionalização da UFMS na sua internacionalização, o decréscimo do aporte financeiro para tais programas coloca em risco o seu andamento, visto que a instituição não tem autonomia financeira para viabilizar a continuidade desses programas.
\end{abstract}

${ }^{1}$ Universidade Federal de Mato Grosso do Sul (UFMS), Campo Grande, Mato Grosso do Sul, Brasil. 
Palavras-chave: internacionalização; Educação Superior; mobilidade discente.

Abstract: Considered one of the fundamental processes for Higher Education nowadays, internationalization encompasses participation in joint research projects; the conformation of interinstitutional curriculum; publication in international vehicles etc. Among its various facets, student mobility is highlighted, involving undergraduate and graduate students. This is the object of this article, which discusses the international student mobility at the Federal University of Mato Grosso do Sul (UFMS), between 2011 and 2017. To this end, we prioritized the study of the Science without Borders Program and the Sandwich Doctorade Program Abroad, which counted on funding from Capes and CNPq. The general objective of the article is to analyze how the implementation of these programs in the UFMS and some impacts of the policies developed there. The data were collected in the management reports of the UFMS, Capes and CNPq, and in the production that analyzes the international student mobility in Brazil. As conclusions, we highlight the way in which such educational policies have induced scientific research in UFMS, by privileging certain areas of knowledge and destination countries. At the same time that these policies have shaped the institutionalization of the UFMS in its internationalization, the decrease of the financial contribution to such programs jeopardise its progress, since the institution has no financial autonomy to enable the continuity of these programmes.

Keywords: internationalization; Higher Education; student mobility.

Resumen: Considerado uno de los procesos fundamentales para la Educación Superior en la actualidad, la internacionalización envuelve la participación en proyectos conjuntos de investigación; la conformación de currículos interinstitucionales; la publicación en vehículos internacionales etc. Entre sus varias facetas destacase la movilidad estudiantil, englobando graduación y post graduación. Ese es el objeto de este artículo, que discute la movilidad estudiantil internacional en la Universidad Federal de Mato Grosso do Sul (UFMS), entre 2011 y 2017. Para tanto, fue priorizado el estudio del Programa Ciencia sin Fronteras y el Programa de Doctorado Sándwich en el Exterior, que contaron con financiamiento de la Capes y del CNPq. El objetivo general del artículo es analizar cómo se materializó la implementación de esos programas en la UFMS y algunos impactos de las políticas allí desarrolladas. Los datos fueron levantados en los informes de gestión de la UFMS, Capes e CNPq y en la producción que analiza la movilidad estudiantil internacional en el Brasil. Como conclusiones, se destaca la forma como tales políticas educacionales indujeron la actividad científica en la UFMS, al privilegiar determinadas áreas del conocimiento y países de destino. Al mismo tiempo que esas políticas dieron forma a la institucionalización de la internacionalización en la UFMS, la disminución del aporte financiero para esos programas coloca en risco su andamiento, dado que la institución no tiene autonomía financiera para viabilizar la continuidad de esos programas.

Palabras clave: internacionalización; Educación Superior; movilidad estudiantil.

\section{INTRODUÇÃO}

Considerado um elemento fundamental do processo de sustentação da sociedade capitalista, a globalização, que marcou todas as etapas de desenvolvimento do capital, como sua condição histórica básica (MELLO, 1999) ganhou, 
entre o final do século XX e início do século XXI, novas formas e conteúdo, que vêm marcando a vida social nos distintos países capitalistas.

Nesse sentido, a educação, como parte da totalidade que se constitui a partir do sistema do capital, também será induzida a transformações decorrentes das mudanças pelas quais passou/passa o capitalismo, na presente quadra histórica. No caso particular da Educação Superior, um dos elementos mais significativos desse processo é, sem dúvida, a internacionalização das instituições de ensino, questão central quando se tem em conta o papel da ciência e da tecnologia no processo globalizado de produção de capital, presente na atualidade.

E, como lembram Pinto e Larrachea (2018, p. 722), “Embora a internacionalização não se reduza somente ao fenômeno da mobilidade estudantil, esta tem sido uma das formas mais visíveis e impactantes da internacionalização da ES". Concordantes com essa questão, elegeu-se como objeto desse artigo a mobilidade discente na UFMS, tendo como objetivo geral analisar os elementos que caracterizaram, entre 2011 e 2017, o envio de estudantes para o exterior.

Para tal análise, foram focados na primeira e segunda partes deste trabalho os dois programas voltados para a mobilidade discente internacional, que contaram com a participação da UFMS: o Programa Ciência sem Fronteiras (CsF), vigente entre 2011 e 2016, que contou com recursos da Coordenação de Aperfeiçoamento de Pessoal de Nível Superior (Capes) e do Conselho Nacional de Desenvolvimento Científico e Tecnológico (CNPq); e o Programa de Doutorado-Sanduíche no Exterior (PDSE), da Capes. Em relação aos dados disponíveis sobre tais programas, serão apresentadas informações sobre a quantidade de alunos atendidos; os países procurados e as áreas do conhecimento que foram contempladas com bolsas do CSF e do PDSE. O acesso às informações pertinentes a tais programas se deu por meio dos relatórios de gestão da UFMS, da Capes e do CNPq, além de dados provenientes de outras pesquisas que versaram sobre a mobilidade estudantil internacional no Brasil.

Por fim, nas conclusões do artigo, procura-se levantar alguns desafios e questões de interesse para a continuidade da política institucional de internacionalização da UFMS, no que diz respeito à mobilidade discente internacional, entre eles, os cortes de verbas públicas para a Educação Superior, em curso no âmbito do governo federal, a partir sobretudo do ano de 2017. 


\section{A MOBILIDADE DISCENTE NA UFMS ENTRE 2011 E 2017: O PROGRAMA CIÊNCIA SEM FRONTEIRAS}

A Universidade Federal de Mato Grosso do Sul (UFMS), instalada em 1962, passou por três etapas, até chegar à sua conformação atual:

1) entre 1962 e 1969, por iniciativa do governo de Mato Grosso², foram criadas e mantidas distintas instituições de Educação Superior (IESS) em cidades da região Sul do estado: em 1962, surgiu a primeira delas, a Faculdade de Farmácia e Odontologia de Campo Grande, na cidade de Campo Grande. Posteriormente, pela Lei n. 2.620/1966, foi instalado o Instituto de Ciências Biológicas de Campo Grande (ICBCG), que absorveu os cursos de Farmácia e Odontologia, criou o curso de Medicina e estabeleceu uma nova estrutura, fundada em departamentos. Por último, nesse primeiro momento, o governo estadual implantou duas outras instituições de Educação Superior, em 1967: em Corumbá, o Instituto Superior de Pedagogia e, em Três Lagoas, o Instituto de Ciências Humanas e Letras.

2) entre 1969 e 1978, esteve presente a Universidade Estadual de Mato Grosso (UEMT), cuja conformação se deu em dois movimentos: o primeiro, que envolveu a integração dos Institutos de Campo Grande, Corumbá e Três Lagoas, pela Lei Estadual n. 2.947/1969; e o segundo, ocorrido em 1970, quando foram criados os Centros Pedagógicos de Aquidauana e Dourados ${ }^{3}$.

3) com a criação do Estado de Mato Grosso do Sul, " [...] foi concretizada a federalização da instituição, que passou a denominar-se Fundação Universidade Federal de Mato Grosso do Sul, pela Lei Federal n. 6.674, de 05.07.1979" (UFMS, s.d.).

Cabe ressaltar que a UFMS, desde sua criação, teve como missão fundamental contribuir com o desenvolvimento regional, especialmente durante o governo cívico-militar, cujo projeto político tinha como objetivo a modernização das forças produtivas e o desenvolvimento do país, para torná-lo competitivo em nível internacional. Para tanto, foram implementadas diversas medidas administrativas para organizar a educação superior no país, entre elas, o processo de expansão de instituições públicas de Educação Superior, que adotaram o modelo

\footnotetext{
${ }^{2}$ Importa destacar que o atual Estado de Mato Grosso do Sul só foi criado em 1977 e sua nova administração efetivamente instalada em 1979.

3 Em 2006, quando pela Lei n. 11.153/2005, o então Campus de Dourados (CPDO) foi transformado na Universidade Federal da Grande Dourados (UFGD).
} 
multicampi, com vistas a promover o desenvolvimento de municípios considerados polos econômicos.

Nessa direção a instituição, ao longo de sua história, continuou com o processo de interiorização, com a criação de outros campi, em 2000 (em Paranaíba) e em 2001 (em Coxim). Posteriormente, durante o governo de Luiz Inácio Lula da Silva, a UFMS passou por uma nova expansão, com a criação de campi na cidade de Nova Andradina (2005); em Chapadão do Sul (2006); em Ponta Porã (2008) e em Naviraí (2009), sendo que estes dois últimos se instalaram no âmbito do Programa de Apoio a Planos de Expansão e Reestruturação das Universidades Federais (REUNI).

Como fruto desse processo, desde 2019 a UFMS contava com 15 unidades setoriais em Campo Grande, abrangendo as três áreas do conhecimento; e outros campi presentes em nove municípios de Mato Grosso do Sul, totalizando cerca de 166 cursos de graduação e 68 cursos de pós-graduação stricto sensu (mestrado, doutorado ou mestrado profissional), além de 27 cursos de especialização.

No tocante à internacionalização,

Embora [...] tenha sido uma questão discutida em distintos momentos da história da educação superior, foi somente entre os anos 1990 e 2000 que se percebem iniciativas mais claras na direção de tornar a internacionalização uma ação constante e complementar ao tripé ensino, pesquisa e extensão. Também no caso da UFMS, sobretudo a partir do PDI 2010-2014, ficou expressa uma intencionalidade em incentivar a internacionalização, sendo que sua concepção e fundamentação baseiam-se no entendimento de transferência de conhecimento, e na focalização da inovação científica e tecnológica. (RODRÍGUEZ; BRITO; PAIVA, 2019, p. 23).

Tal perspectiva, apontada pelas autoras em relação à internacionalização na UFMS em todas as suas dimensões - mobilidade acadêmica (discente, docente e de servidores técnico-administrativos), projetos de pesquisa com interface internacional, produção científica internacionalizada (artigos em periódicos, livros, apresentação de trabalhos em eventos científicos etc.), entre outros-, colocou-se também, como assinalado, em relação à mobilidade discente.

Nesses termos, passa-se agora a considerar o que foi a mobilidade discente internacional na UFMS, entre 2011 e $2017^{4}$, o que coincide com o período em que

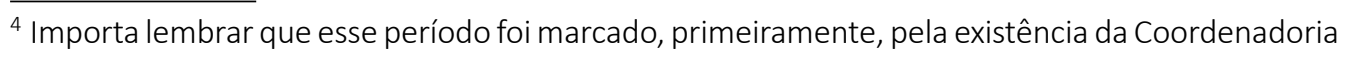


tais ações ganharam maior volume na instituição. Primeiramente, é importante destacar que houve dois momentos nessa trajetória: aquela que se estendeu de 2011 a 2014, que se relaciona com o processo de criação e implementação das fases 1 e 2 do Programa Ciência sem Fronteiras (SANTOS CARVALHO, 2015), no qual se intensificou a ida de estudantes para o exterior, sobretudo no âmbito dos cursos de graduação; e um segundo momento, abrangendo os anos $2015^{5}$ a 2017, quando houve um decréscimo na mobilidade discente internacional, principalmente entre os discentes da graduação, quando o CsF foi suspenso.

O movimento que envolveu a mobilidade discente internacional na UFMS pode ser visualizado na tabela 1, que reúne os dados disponíveis nos Relatório de Gestão da UFMS, nos seis anos considerados - 2011 a 2017. Destaque-se que, como dito anteriormente, houve primeiramente um crescimento expressivo no número de discentes em situação de mobilidade internacional entre 2011 e 2014 (crescimento de 480,0\%, saindo de 50 discentes em 2011 para 240 em 2014).

Tabela 1 - Discentes em mobilidade internacional na UFMS* - 2011 a 2017**

\begin{tabular}{l|c|c|c|c|c|c|c}
\hline Ano & 2011 & 2012 & 2013 & 2014 & 2015 & 2016 & 2017 \\
\hline Meta UFMS & 40 & 40 & 40 & 40 & 60 & 60 & n.d. \\
\hline TOTAL DE DISCENTES & $\mathbf{5 0}$ & $\mathbf{9 9}$ & $\mathbf{1 2 0}$ & $\mathbf{2 4 0}$ & $\mathbf{1 6 4}$ & $\mathbf{5 1}$ & $\mathbf{3 0}$ \\
\hline
\end{tabular}

n.d. - informação não disponível.

* Como os dados se referem aos discentes que se encontravam no exterior no referido ano, discentes cujas bolsas abrangeram semestres de anos distintos foram contabilizados mais de uma vez.

** Não estão incluídas nos dados da tabela as bolsas concedidas para docentes da instituição.

Fontes: UFMS (2012-2018; 2020); CAPES (2019).

de Relações Institucionais, ligada à Pró-Reitoria de Planejamento (PROPLAN), que administrava todas as atividades externas da UFMS, tanto no plano nacional como internacional. Somente no segundo semestre de 2011 foi criada a Coordenadoria de Relações Internacionais, que foi mantida até 2016, tendo sido vinculada diretamente à Reitoria. Já em 2017 surgiu a "Divisão de Relações Internacionais (DIRIN), que, funcionando junto à Agência de Desenvolvimento, Inovação e Relações Internacionais (AGINOVA), tornou-se responsável '[...] pela elaboração, coordenação e execução das políticas de cooperação internacional na UFMS'" (UFMS, 2018 apud RODRÍGUEZ; BRITO; PAIVA, 2019, p. 24).

${ }^{5}$ Em 2014, ocorreram os últimos processos seletivos para o programa de graduação-sanduíche pelo CsF, que enviaram discentes para o exterior entre fevereiro e setembro de 2015 (CNPq; CAPES, 2016a). 
Internacionalização da Educação Superior: a questão da mobilidade discente na Universidade Federal de Mato Grosso do Sul, UFMS (2011-2017)

Já entre 2014 e 2015 há um decréscimo no número de alunos em mobilidade internacional de 31,7\%, tendo-se passado de 240 em 2014 para 164 em 2015. Essa queda foi acentuada em 2016: se comparados com 2014, os 51 discentes em mobilidade internacional em 2016 representam apenas $21,3 \%$ do total de alunos que se encontravam realizando parte de seus cursos no exterior, em 2014. Em outros termos, houve uma queda de $78,7 \%$ na mobilidade discente internacional na UFMS entre 2014 e 2016, em grande medida provocada pela desativação do Programa Ciência sem Fronteiras. Finalmente, em 2017, contou-se com 26 bolsas do Programa Doutorado-Sanduíche no Exterior, da Capes, por um lado; e, por outro, em termos de graduação, foram quatro cotas do Programa Bolsas LusoBrasileiras Santander Universidades, totalizando 32 discentes $^{6}$ em mobilidade internacional na UFMS, no referido ano.

Nesse sentido, e visando apresentar mais detidamente esse primeiro momento, note-se também que as metas institucionais relativas ao indicador "aumento do número de vagas para mobilidade estudantil internacional" foram atingidas entre 2011 e 2015. Assim, as vagas ofertadas ultrapassaram, em 2011, $12,5 \%$ da meta estabelecida (50 vagas oferecidas, para uma meta inicial de 40 vagas no ano) e chegaram, no ano mais expressivo, 2014, a ultrapassar em 600,0\% a expectativa inicial em relação ao número de discentes em mobilidade internacional, que era de 40 alunos. Em outros termos, em 2014, quando a UFMS tinha 14.306 alunos, $1,68 \%$ do seu corpo discente estava envolvido com distintas formas de mobilidade estudantil internacional, principalmente graduação-sanduíche e doutorado-sanduíche.

Em relação ao tipo de mobilidade discente hegemônica nesse primeiro período que se estendeu de 2011 a 2015, como já afirmado, foi fundamental a indução das políticas governamentais, via agências de fomento - Capes e CNPq -, parti-

\footnotetext{
${ }^{6}$ No relatório de gestão da UFMS para o ano de 2017 (UFMS, 2018), são citados vários convênios internacionais que foram firmados naquele ano, como a associação ao Consórcio Erasmus Mundus - Projeto Euro-Brazilian Windows + e a celebração de instrumentos jurídicos internacionais com pelo menos outras 20 instituições de Educação Superior, principalmente europeias. Não são informados, contudo, dados sobre a mobilidade de discentes para esses países. Ao mesmo tempo, o CNPq, depois que foram encerradas as atividades do Programa Ciência sem Fronteiras, em 2015/2016, ofereceu novas bolsas para mobilidade estudantil na modalidade doutorado-sanduíche (82 bolsas) em 2017 (Edital Bolsas Especiais 2017 - País e Exterior). Até o momento, não foram encontradas informações sobre a obtenção de tais bolsas por discentes da UFMS.
} 
cularmente aquelas advindas da execução do Programa Ciência sem Fronteiras. Dada a importância desse programa, são apresentados a seguir os dados relativos à implementação do CsF na UFMS (tabela 2).

Tabela 2 - Quantitativo de bolsas do Programa CsF na UFMS, por modalidade 2011 a 2016

\begin{tabular}{|c|c|c|}
\hline Modalidade & Quantitativo & $\%$ \\
\hline Graduação-sanduíche & 338 & 88,0 \\
\hline Doutorado-sanduíche & 33 & 11,0 \\
\hline Doutorado no exterior & 3 & \multirow{4}{*}{1,0} \\
\hline Pós-Doutorado no exterior & 5 & \\
\hline Atração de jovens talentos & 2 & \\
\hline Pesquisador visitante & 1 & \\
\hline TOTAL & 382 & 100,0 \\
\hline
\end{tabular}

Fonte: CNPq; CAPES (2016b).

Fica evidenciado, pela tabela 2, a importância do CsF para a mobilidade discente internacional, sobretudo nos cursos de graduação. De fato, a mobilidade discente envolvendo a graduação-sanduíche manteve-se presente e forte na UFMS, principalmente até 2015, graças a esse programa. Em que pese a presença de outras ofertas de mobilidade estudantil pelos Programas Santander Top Espanha e Bolsas Luso-Brasileiras Santander Universidades; Programa de Mobilidade Mercosul (PMM) ${ }^{8}$; Capes Fipse9; projeto Euro-Brazilian Windows + (com o apoio financeiro da Comissão Europeia, por meio do Programa Erasmus Mundus) ${ }^{10}$, entre outros; a mobilidade estudantil financiada pela própria UFMS,

${ }^{7}$ Cf. https://www.santander.com.br/universidades/formacao para mais informações sobre esses programas.

${ }^{8}$ Sobre o PMM cf.: http://www.mercosul.gov.br/o-mercosul-na-vida-do-cidadao/ sistema-integrado-de-mobilidade-do-mercosul.

${ }^{9} \mathrm{O}$ Capes-Fipse (Fund for the Improvement of Post Secondary Education - Fipse), programa de consórcios em Educação Superior entre Brasil e Estados Unidos, com financiamento do Departamento de Educação do governo americano e da CAPES, tinha como objetivo inserir as instituições de Educação Superior no cenário internacional, com apoio financeiro para intercâmbio de estudantes e missões de trabalho de docentes. Foi desativado em 2012. Cf. http://capes.gov. br/36-noticias/4499-capes-e-fipse-selecionam-propostas-de-cursos-de-graduacao.

${ }^{10}$ Cf. https://ebwplus.up.pt/. 
em uma iniciativa única em 2012, envolvendo 40 alunos que se deslocaram para a vizinha Bolívia; e dois casos de mobilidade autofinanciada, um para Portugal, em 2013, e outro para a Hungria, em 2015, a maior parte dos deslocamentos foi bancada pelo CsF. E, nesta direção, o deslocamento de alunos de graduação para o exterior em grande escala, como lembra Silva Carvalho (2015), não ocorreu mais na UFMS a partir de 2016/2017.

Outro elemento a ser destacado, por meio da tabela 3, são as principais áreas que foram priorizadas pelo Programa CsF na UFMS, dado que deve ser considerado ao se verificarem quais foram os destinos fundamentais dos bolsistas.

Ora, os dados da tabela 3, que mostram as áreas prioritárias do CsF na UFMS, são coincidentes, salvo algumas poucas diferenças, com as áreas que se mostraram como prioridades no âmbito nacional, quando consideradas as 92.880 bolsas (CNPq; CAPES, 2016a) implementadas pelo programa. Isso revela, por um lado, a forte indução das políticas federais de ciência e tecnologia no país, principalmente quando se consideram as instituições de médio e pequeno porte públicas, mais diretamente dependentes de recursos federais para a implementação de políticas de internacionalização. Por outro lado, quando se considera o objetivo fundamental do Programa, as áreas em destaque, consideradas prioritárias, vêm ao encontro do proposto pelo CsF:

O objetivo do Programa Ciência sem Fronteiras é a formação de recursos humanos altamente qualificados nas melhores universidades e instituições de pesquisa estrangeiras, com vistas a promover a internacionalização da ciência e tecnologia nacional, estimular pesquisas que gerem inovação e, consequentemente, aumentar a competitividade das empresas brasileiras. Esse objetivo será concretizado por meio da expansão significativa do intercâmbio e da mobilidade de graduandos, pós-graduandos, pesquisadores e docentes brasileiros no exterior. (CNPq; CAPES, 2011, p. 1, grifos do autor). 
Tabela 3 - Áreas prioritárias no Programa CsF na UFMS - 2011 a 2016

\begin{tabular}{l|c|c}
\hline \multicolumn{1}{c|}{ Área } & Bolsas concedidas & $\mathbf{\%}$ \\
\hline Engenharias e demais áreas tecnológicas & 155 & 40,6 \\
\hline Biologia, Ciências Biomédicas e da Saúde & 81 & 21,2 \\
\hline Computação e Tecnologias da Informação & 42 & 11,0 \\
\hline Indústria Criativa & 27 & 7,1 \\
\hline Ciências Exatas e da Terra & 25 & 6,5 \\
\hline Produção Agrícola Sustentável & 15 & 3,9 \\
\hline Novas Tecnologias de Engenharia Construtiva & 11 & 2,8 \\
\hline Biodiversidade e Bioprospeção & 9 & 2,4 \\
\hline Energias Renováveis & 6 & 1,6 \\
\hline Fármacos & 3 & 0,8 \\
\hline Formação de Tecnólogos; Nanotecnologia e Novos & 3 & 0,8 \\
\hline Materiais; Petróleo, Gás e Carvão Mineral & 2 & 0,5 \\
\hline Tecnologias de Prevenção e Mitigação de Desastres & 3 & 0,8 \\
\hline Não informados & $\mathbf{3 8 2}$ & $\mathbf{1 0 0 , 0}$ \\
\hline TOTAL & &
\end{tabular}

Fonte: CNPq; CAPES (2016b).

Assim, como lembram Chaves e Castro (2016) e Silva Júnior e Kato (2016), o Programa Ciência sem Fronteiras era parte de uma estratégia mais ampla, no campo da política pública para a ciência e tecnologia no Brasil, pensada na perspectiva de ajustar ainda mais a produção científica brasileira às demandas do capital globalizado, produzindo profissionais, como afirmado acima, comprometidos com a "inovação"/"competitividade", ou seja, com o empreendedorismo tão caro ao sistema do capital.

E, em função dessa perspectiva, foram exatamente as áreas mais sensíveis às necessidades do capital no século XXI, aquelas que devem dar respostas mais efetivas às demandas de simplificação/objetivação dos processos produtivos em curso - tais como as Engenharias, as Ciências Biológicas e a Computação - ou, como lembram Silva Júnior e Kato (2016), que podem colaborar para diminuir o gap entre ciência e tecnologia, as mais diretamente fomentadas por meio das agências públicas de financiamento, Capes e CNPq.

Tal processo de indução levou a uma outra consequência, relacionada a esta perspectiva de formar pesquisadores voltados aos interesses do mercado capitalista: quando examinados os países de destino, recoloca-se a questão das relações 
de dominação/subordinação entre os países centrais e periféricos, no sistema do capital. Assim, quando são examinadas as informações acerca do destino dos estudantes da UFMS contemplados com bolsas do CsF, a América do Norte (EUA e Canadá) e a Europa têm a primazia, seguidas pela Ásia - mais especificamente, Japão -, além da Oceania (Austrália e Nova Zelândia) (tabela 4).

Tabela 4 - Países de destino dos bolsistas do Programa CsF na UFMS - 2011 a 2016

\begin{tabular}{l|c|c}
\hline País & Bolsas & $\mathbf{\%}$ \\
\hline EUA & 161 & 42,1 \\
\hline Canadá & 36 & 9,4 \\
\hline Austrália & 33 & 8,6 \\
\hline Espanha & 25 & 6.5 \\
\hline Reino Unido & 21 & 5,5 \\
\hline Hungria & 20 & 5,2 \\
\hline Irlanda & 20 & 5,2 \\
\hline Itália & 17 & 4,5 \\
\hline Alemanha & 11 & 2,9 \\
\hline França & 9 & 2,4 \\
\hline Portugal & 8 & 2,1 \\
\hline Holanda & 7 & 1,8 \\
\hline Japão & 6 & 1,6 \\
\hline Brasil & 3 & 0,8 \\
\hline Nova Zelândia & 2 & 0,5 \\
\hline Bélgica & 1 & 0,3 \\
\hline Finlândia & 1 & 0,3 \\
\hline Não especificado & 1 & 0,3 \\
\hline TOTAL & $\mathbf{3 8 2}$ & $\mathbf{1 0 0 , 0}$ \\
\hline
\end{tabular}

Fonte: CNPq; CAPES (2016b).

Em relação à tabela 4, pode-se observar o seguinte:

a) apresenta-se a mesma tendência à concentração dos destinos dos bolsistas numa direção Sul-Norte, com predominância de instituições norte-americanos (42,1\% dos bolsistas se dirigiram para instituições de Educação Superior americanas, ou seja, quase a metade dos estudantes se concentraram naquele país). A concentração para o caso brasileiro, no entanto, atingiu 30,0\% das bolsas, isto é, apresentou uma variação para baixo, quando comparado aos dados da UFMS. 
b) entre os 12 países mais bem ranqueados, 11 aparecem nas duas listagens, tanto para o Brasil como para a UFMS. A única diferença está na sexta colocação na UFMS, ocupada pela Hungria, que aparece na 12a colocação no caso do Brasil. Neste último, em $11^{\circ}$ lugar, apareceu a Holanda, 12a colocada no caso da UFMS. Em relação à Hungria, destacam-se a escolha de suas instituições principalmente nas áreas das engenharias.

c) destaque-se ainda o caso da mobilidade para o Brasil, no Programa CsF, somando três pesquisadores, entre 2011 e 2016. Ora, um dos objetivos do programa era atrair pesquisadores/talentos para o Brasil. Nesse sentido, Pinto e Larrachea (2018, p. 724) lembram que "Argentina, Brasil, Chile, Equador, México e Venezuela, juntos, apresentam um saldo bruto de mobilidade negativa que é, na média anual, de quase (-)73 mil estudantes", ou seja, exportam muito mais estudantes do que recebem de outros países, notadamente nas suas relações de intercâmbio com os países centrais. Exatamente o contrário acontece com os Estados Unidos e o Reino Unido, segundo os mesmos autores, que receberam muito mais alunos do que enviaram para fora de suas fronteiras.

Indo na mesma direção, Contel e Lima (2007) levantam outros elementos a serem considerados na análise do que denominam uma nova geopolítica do conhecimento, estabelecida sobretudo a partir dos anos 1990, a qual tem na mobilidade estudantil um dos seus elementos fundamentais. Aliás, os autores lembram que a mobilidade estudantil ainda é a forma mais difundida de internacionalização da Educação Superior. Com base em Knight (2003 apud CONTEL; LIMA, 2007, p. 181), destacam que a divisão do trabalho que faz dos países capitalistas centrais produtores de conhecimentos

[...] faz com que cada vez mais as instituições de ensino superior dos países-líderes se especializem no recebimento destes fluxos. [...] [Pois] "o movimento de pessoas" é visto como mais importante que o "movimento de programas", da "importação/exportação comercial" e do "estabelecimento de campi avançados" (branch campuses).

Complementarmente, mas não menos significativa, coloca-se ainda a questão da atração de cérebros como outra consequência desse processo. Além disso, a mobilidade estudantil se tornou também um elemento dinamizador das economias dos países que recebem alunos, já que estes últimos, numa perspectiva mercadológica, são potenciais consumidores: dos próprios serviços educacionais, 
de moradia, alimentos, lazer, transportes, materiais de pesquisa, entre outros (CONTEL; LIMA, 2008) ${ }^{11}$.

Finalizando, os autores chamam ainda a atenção para um outro dado:

No início do processo de internacionalização da ES, a mobilidade estudantil estava centrada nos programas de pós-graduação stricto sensu, no entanto, na década de 1990 em diante, os países hegemônicos iniciam um processo de ampliação da sua influência sobre o sistema mundial de educação, atraindo estudantes de graduação. (PINTO; LARRECHEA, 2018, p. 724).

No caso do Brasil, em geral, e da UFMS, em particular, o Programa CsF representou um dos momentos desse processo de internacionalização, respondendo à necessidade de ampliação da influência dos centros de ensino dos países hegemônicos sobre o ensino de graduação. Uma vez encerrado o programa, o que se colocou no horizonte da mobilidade discente internacional? É o que será tratado a seguir, por meio da apresentação do Programa de Doutorado-Sanduíche no Exterior.

\section{A MOBILIDADE DISCENTE NA UFMS ENTRE 2011 E 2017: O PROGRAMA DE DOUTORADO-SANDUÍCHE NO EXTERIOR (PDSE)}

Cabe lembrar que, desde 2011, no caso da Capes, o PDSE é considerado institucional ${ }^{12}$, visto que seria responsabilidade da Pró-Reitoria de Pós-Graduação de cada instituição o gerenciamento das cotas, o acompanhamento das candidaturas, bem como a orientação e a divulgação dos resultados aos candidatos dos programas de pós-graduação. A estes últimos, com anuência das respectivas

\footnotetext{
${ }^{11}$ Nessa perspectiva de constituição de uma geopolítica do conhecimento, envolvendo a totalidade do mundo capitalista, seria interessante considerar o papel do Brasil em relação aos países africanos e latino-americanos, já que, no mesmo momento histórico em que se fomentava a mobilidade internacional Sul-Norte, também foi alvo de incentivos estatais a mobilidade Sul-Sul, com o Brasil atuando como receptor de estudantes africanos e de distintos países latino-americanos, por meio do Programa de Estudantes-Convênio de Graduação (PEC-G) e do Programa de Estudantes-Convênio de Pós-Graduação (PEC-PG), entre outros. Cf. MEC (BRASIL, 2019).

${ }^{12} \mathrm{O}$ oferecimento de bolsas-sanduíche para o exterior, em nível de doutorado, no caso do CNPq, continua se dando por meio de demanda direta do candidato, a chamada "bolsa balcão". Em função disso, torna-se particularmente difícil a coleta de informações sobre elas, pois ficam na dependência de informações fornecidas por cada Programa de Pós-Graduação (PPG). Em função disso, optou-se por tratar apenas do programa PDSE, da Capes.
} 
instituições, caberia a seleção inicial dos bolsistas (CAPES, 2019). O programa foi alvo de outra regulamentação por meio da Portaria Capes n. 69, de 2 de maio de 2013. Segundo o art. 10 da referida portaria, o objetivo do programa é

A modalidade de intercâmbio e mobilidade internacional de estudantes brasileiros regularmente matriculados em cursos de Doutorado no Brasil para realização de estágio de doutorado em universidades no exterior, aqui denominado modalidade Doutorado Sanduíche no Exterior é uma atividade própria da educação com o objetivo de oferecer bolsas de estágio de doutorado de forma a complementar os esforços despendidos pelos programas de pós-graduação no Brasil, na formação de recursos humanos de alto nível para inserção no meio acadêmico, de ensino e de pesquisa no país. (CAPES, 2013).

Nessa condição, segundo o artigo $13^{\circ}$, cada programa de doutorado institucionalizado nas diferentes IESs faria jus a duas cotas de 12 meses cada um, sendo que o tempo mínimo de permanência no exterior seria de três meses. Em outros termos, se o programa optasse por enviar bolsistas que realizassem estágio de três meses, poderia enviar até oito bolsistas/ano.

Além disso, no $\S 3^{\circ}$ do mesmo artigo $13^{\circ}$, estabelecia-se importante ressalva para a implementação do PDSE, a partir de 2013: aos programas pertencentes às grandes áreas das Ciências Biológicas, Agrárias, Exatas e da Terra, bem como as Engenharias, consideradas prioritárias pelo Decreto n. 7.642, de 13 de dezembro de 2011, que regulamentou o Programa Ciência sem Fronteiras, caberia " [...] uma cota adicional, correspondente a 12 mensalidades, podendo atender adicionalmente de um a quatro bolsistas" (CAPES, 2013, p. 5, grifos no original). Ainda no parágrafo $4^{\circ}$, ficava estabelecido que também teriam direito automaticamente à cota adicional os programas de pós-graduação relacionados com as áreas de Farmácia, Medicina, Odontologia, Desenho Industrial, bem como inseridas em Geografia (subárea Geografia Física), Administração (Administração de Setores Específicos: Produção e Inovação Tecnológica) e Psicologia (subáreas de Psicometria, Psicologia Experimental, Psicologia do Trabalho e Organizacional).

Além dessas, outras diretrizes foram sendo adicionadas pela Capes, no tocante à internacionalização da pós-graduação no país, a partir de 2013:

1. A Diretoria de Bolsas e Programas no país (DBP/Capes) passou a oferecer, ainda em 2013, aos programas de pós-graduação que enviam discentes para o doutorado-sanduíche no exterior, por um período mínimo de 9 meses, uma 
cota adicional de bolsa de mestrado dos programas de Demanda Social (DS); de Excelência Acadêmica (PROEX, dirigido aos programas com notas 6 e 7 nas avaliações realizadas pela Capes); e do Programa de Suporte à Pós-Graduação de Instituições de Ensino Particulares (PROSUP). Nesse sentido, foram concedidas, em 2014, 1.387 bolsas adicionais de doutorado (CAPES, 2014-2018).

2. Em 2017, destaque-se que, no tocante à internacionalização da pós-graduação, a Capes disponibilizou, por meio do Edital n. 47/2017 - PDSE, uma cota de doutorado-sanduíche para cada um dos programas de doutorado no Brasil com nota superior a 4 (quatro) na última avaliação quadrienal (2013-2016) (CAPES, 2014-2018).

Considerando os critérios anteriormente delineados, a UFMS lançou, em 2011, o Edital n. 64, de 29 de setembro de 2011 (UFMS, 2011), que regulamentava a seleção prévia de candidatos ao PDSE, em fluxo contínuo, para o ano de 2012, segundo o artigo 10 do Regulamento da Capes então em vigor. Eram previstas, para 2012, uma cota de duas bolsas por programa de pós-graduação (PPG) com doutorado da UFMS: PPG em Ciência Animal; PPG em Ciência da Computação; PPG em Doenças Infecciosas e Parasitárias; PPG em Ecologia e Conservação; PPG em Educação; PPG em Saúde e Desenvolvimento na Região Centro-Oeste; PPG em Tecnologias Ambientais. Ainda era previsto, no item 1.3.1, o remanejamento de cotas entre os PPGs, no caso de vagas não preenchidas ${ }^{13}$.

Nos anos de 2013 a 2017, com a progressiva importância que a internacionalização foi ganhando para os PPGs, o volume de cotas para o PDSE aumentou, tendo sido acrescido com as bolsas de doutorado-sanduíche provenientes do CsF. Além disso, como dito anteriormente, as áreas priorizadas pelo CsF podiam ser contempladas com cotas adicionais de bolsas PDSE.

Assim, entre 2013 e 2017, foram concedidas 32 bolsas PDSE para a UFMS, distribuídas nos seguintes quantitativos, por ano:

2013 - 9 cotas; 2014 - 13 cotas; 2015 - 19 cotas; 2016 - 9 cotas (CAPES, 2016).

Essas cotas, que somadas totalizam 50 unidades, foram acessadas por 32 bolsistas, uma vez que uma mesma cota pode ser dividida por até 3 bolsistas. Por fim, no ano de 2017, 26 bolsistas estavam em mobilidade internacional, via PDSE (CAPES, 2017; UFMS, 2020).

${ }^{13}$ Não há informações, até o momento, sobre como se deu a utilização dessa cota de bolsas do PDSE. 
A maior parte delas foi distribuída entre as áreas prioritárias do Programa Ciência sem Fronteiras, sendo que os programas contemplados, em ordem decrescente em relação ao número de bolsas, foram: Programa de Pós-Graduação em Ecologia e Conservação; Programa de Pós-Graduação em Biotecnologia e Biodiversidade; Programa de Pós-Graduação em Química. Somente no ano de 2016, com deslocamento entre março e outubro de 2017, foram alocadas as primeiras três cotas para o PPG em Educação/Campo Grande; e o PPG em Letras/ Três Lagoas. Em outras palavras, e considerando que o CsF abria a possibilidade de aumentar as cotas do PDSE para as áreas consideradas prioritárias, só recentemente, quando o CSF já não se encontrava mais em vigor, o PDSE foi estendido aos programas de pós-graduação da área de Ciências Humanas da UFMS.

Da mesma forma que na graduação, os países mais procurados pelos discentes de pós-graduação em mobilidade internacional foram: Estados Unidos (14 cotas); Espanha (11 cotas); Portugal (quatro cotas); Canadá (três cotas); França (três cotas); Argentina (três cotas). Juntos, esses seis países atenderam 76,0\% dos cotistas do PDSE na UFMS, entre 2013 e 2016. Os 24,0\% das cotas restantes dividiram-se entre Alemanha, Suíça, Austrália, Reino Unido, Holanda e Irlanda (CAPES, 2016).

Ainda tratando da internacionalização da pós-graduação, também no ano de 2017 foi lançado o Edital n. 41/2017 do Programa Institucional de Internacionalização (CAPES-PrInt), com o objetivo de

[...] fomentar a construção, a implementação e a consolidação de planos estratégicos de internacionalização de instituições, estimular a formação de redes de pesquisas internacionais com foco no aprimoramento da qualidade da produção acadêmica vinculada à pós-graduação, ampliar as ações de apoio à internacionalização na pós-graduação. (CAPES, 2014-2018, p. 55).

O Capes-PrInt, ao contrário de outras ações da Capes no campo da internacionalização da pós-graduação brasileira até então, não tem caráter universal, pois visa financiar até 40 projetos institucionais de internacionalização com duração de 4 anos, fazendo de cada instituição a responsável pela estruturação e apresentação do seu próprio plano de internacionalização, na medida, inclusive, em que prevê a organização de um comitê gestor para tal. Nesse sentido, também foram as próprias IESs contempladas que estabeleceram suas "vocações" institucionais, demandas específicas, prioridades e mecanismos para ampliar o desempenho da pesquisa e da pós-graduação. 
Frise-se que, não tendo caráter amplo, o Programa Capes-PrInt

[...] prevê a criação de uma estratégia de excelência com três iniciativas: uma, complementar ao Capes-PrInt, será voltada para a construção de estratégias institucionais de internacionalização; outra consiste na criação de hotspots (pontos de excelência) vinculados a demandas do setor produtivo visando a excelência na produção de conhecimento e de tecnologias voltadas à solução de problemas. A última fomentará a criação de clusters de excelência em pesquisa básica e aplicada formados por pesquisadores de uma mesma instituição ou por um grupo de cientistas de instituições geograficamente próximas para desenvolver projetos de pesquisa em domínios de competitividade internacional. (CAPES, 2014-2018, p. 55).

Em outras palavras, com o Capes-PrInt, o processo de internacionalização da Educação Superior, por um lado, volta a priorizar a pós-graduação, o que já vinha acontecendo principalmente a partir de 2016, quando foi descontinuado o CsF; por outro lado, fica explícita a diretriz do órgão de Estado mais importante para a pós-graduação no Brasil no sentido de formação de centros de excelência na produção de conhecimento e, em especial, conhecimento capaz de gerar novas tecnologias, que atendam aos interesses do mercado, voltadas aos setores produtivos. Essa seria, finalmente, a forma de colocar o país em condições de competitividade no mercado internacional.

Na UFMS, os programas que tiveram seus projetos aprovados na seleção realizada pela Pró-Reitoria de Pesquisa e Pós-Graduação foram os seguintes:

1) Ecologia e Conservação

2) Química

3) Doenças Infecciosas e Parasitárias

4) Tecnologias Ambientais

5) Química

6) Ciência Animal

7) Bioquímica e Biologia Molecular

8) Letras

9) Administração

Como o Capes-PrInt prevê a concessão de recursos específicos para as instituições e respectivos programas de pós-graduação envolvidos em suas ações, a partir de 2018 o PDSE se tornou acessível apenas àquelas áreas da pós-graduação que, nas IESs contempladas, não estão envolvidas no programa. 


\section{4 À GUISA DE CONCLUSÃO: A FORMAÇÃO DO CIDADÃO DO MUNDO}

Encerrando este artigo, é oportuno trazer à lembrança as palavras de Octávio Ianni, na conferência denominada "O cidadão do mundo":

No vasto e intrincado cenário mundial, nesse novo palco da história, está em curso a formação de um outro indivíduo, que pode ser um novo, diferente e problemático cidadão. [...] Trata-se de reconhecer que os indivíduos e as coletividades, os povos e as nações, as culturas e as civilizações, estão inscritos e dinamizados, organizados e desafiados, pelas relações, processos e estruturas que se desenvolvem em escala mundial; lembrando [...] [da] globalização, com a qual se forma a sociedade civil mundial em toda a sua complexidade, histórica e lógica, à qual subsumem-se praticamente todas as outras realidades. Esse o contexto histórico-social em que se forma o novo indivíduo e, provavelmente, o novo cidadão. (IANNI, 2004, p. 30)

Ora, é no palco da história, no qual toda a sociedade está imersa, que A Educação Superior é chamada a responder aos desafios postos pela sociedade capitalista globalizada, seja no sentido de reafirmá-la, seja na direção de contestá-la. No sentido da reafirmação do ethos capitalista, é necessário pensar numa educação global que valide, tanto prática quanto ideologicamente, a primazia do mercado, da ciência que se verga aos interesses do capital. Uma ciência que se afirme pela negação das necessidades da maioria trabalhadora, em nome de uma inserção internacional que, no caso dos países periféricos, significa seu atrelamento aos circuitos dominantes do mundo globalizado. Nessa direção, tão bem expressa em propostas como aquela que fundamenta o Programa Capes-PrInt, propõe-se a constituição das assim chamadas Universidades de Classe Mundial, cujas características centrais seriam, como afirma Thiengo (2019, p. 16), seu “[...] alto nível de internacionalização (para atração de talentos); investimento alto e diversificado; gestão flexível e transferência de tecnologia/interação com o setor produtivo (inovação), entre outras".

Na perspectiva da contestação a essa proposição, coloca-se uma instituição universitária que, sem negar - até porque isso seria a-histórico - este momento que coloca novos desafios para a sociedade do século XXI, assume-se como parte importante, mesmo que não decisiva, do processo de conformação de um novo e problemático cidadão, que necessita do conhecimento científico para a sua formação. Nessa direção, reconhece-se a ciência, em todas as suas áreas e dimen- 
sões, como patrimônio coletivo, instrumento importante tanto para o domínio da natureza quanto para a equalização das graves questões sociais.

Nessa direção, a mobilidade internacional no campo da Educação Superior torna-se decisiva, pois o cidadão do mundo será aquele capaz de entender e atuar neste mundo globalizado, no qual os desafios também estão colocados numa dimensão mundializada. Ora, esta proposta de mobilidade, que deve ser acessível a todo o multifacetado universo acadêmico, vai na contramão de projetos como o Ciência sem Fronteiras, na medida em que este último projetou, via mercado, uma mobilidade restrita, tanto social como geograficamente, como também vai na contramão de projetos como o Capes-PrInt, que fossiliza ainda mais a já precária mobilidade internacional proposta na primeira década do século XXI, ao colocar como seu pressuposto a busca pela excelência acadêmica, leia-se, empreendedorismo e submissão às diretrizes do capital.

Ainda mais: no momento em que, por força das necessidades impostas por tais programas, no caso da UFMS, a instituição se viu impelida a organizar-se, institucionalmente (UFMS, 2018), para fazer frente às novas demandas emanadas dos processos de internacionalização em curso, por exemplo, destinando recursos próprios para programas de suporte a alunos e professores em termos de mobilidade e/ou de publicações internacionalizadas, tais iniciativas são abortadas, seja pela imposição de cortes no financiamento público para as IFES, que atinge duramente as propostas para internacionalização; seja pelas próprias imposições advindas de programas como o Capes-PrInt, que tem na excelência de poucos e para poucos sua mola mestra. Além disso, a invisibilidade das ciências humanas nos processos de internacionalização indica as características desejadas no que se refere à constituição de tais cidadãos, quando a produção do conhecimento é reconhecida somente se o produto for comercializável e a valorização recai sobre os resultados, sem serem considerados os processos nos quais foram geradas tais ações.

No entanto, como o palco da história está em aberto, também estão em processo todas as possibilidades, que se apresentam em disputa nesse, como em outros momentos históricos. Continua colocado, portanto, o desafio pela constituição do cidadão do mundo, com base numa internacionalização cidadã. 


\section{REFERÊNCIAS}

BRASIL. Ministério da Educação. Portal PEC-G. Brasília, 2019. Disponível em: http://portal. mec.gov.br/pec-g. Acesso em: 5 out. 2019.

BRASIL. Ministério das Relações Exteriores. Programa de Estudantes-Convênio de PósGraduação - PEC-PG. Brasília, 2019. Disponível em: http://www.dce.mre.gov.br/PEC/ PECPG.php. Acesso em: 5 out. 2019.

CAPES. Programa de Doutorado-Sanduíche no Exterior (PDSE). Brasília, 2019. Disponível em: https://www.capes.gov.br/bolsas-e-auxilios-internacionais/pais/218-multinacional/9660programa-de-doutorado-sanduiche-no-exterior-pdse. Acesso em: 15 set. 2019.

CAPES. Portal da transparência: pesquisa por instituição de vínculo do bolsista - UFMS. Brasília, 2017. Disponível em: http://transparencia.capes.gov.br/transparencia/xhtml/ PesquisaEntidadeEnsino.faces. Acesso em: 29 set. 2019.

CAPES. Bolsas Ativas em Programas de Mobilidade Internacional 2013 a 2016. Brasília, 2016. Disponível em: https://dadosabertos.capes.gov.br/dataset/bolsas-programasmobilidade-internacional-2013-a-2016. Acesso em: 25 set. 2019.

CAPES. Relatórios de gestão dos exercícios: exercícios de 2013 a 2017. Brasília, 20142018. Disponível em: https://www.capes.gov.br/acessoainformacao/auditorias. Acesso em: 28 set. 2019.

CAPES. Portaria n. 69, de 2 de maio de 2013. Aprovar o Regulamento do Programa de Doutorado-Sanduíche no Exterior - PDES. Brasília, 2013. Disponível em: https://www.capes.gov.br/images/stories/download/legislacao/Portaria_069_ RegulamentaPDSE_22Maio2013.pdf. Acesso em: 16 set. 2019.

CHAVES, Vera Lúcia Jacob; CASTRO, Alda Maria Duarte Araújo de. Internacionalização da educação superior no Brasil: programas de indução à mobilidade estudantil. Revista Internacional de Educação Superior, Campinas, SP, v. 2, n. 1, p. 118-37, jan./abr. 2016.

CNPq. Bolsas especiais no país e no exterior: resultados. Brasília, 2017. Disponível em: http://www.cnpq.br/web/guest/chamadas-publicas?p_p_id=resultadosportlet_WAR_ resultadoscnpqportlet_INSTANCE_OZaM\&filtro=resultados\&startPage=1\&buscaChama $\mathrm{da}=\& a n o=2017$. Acesso em: 15 set. 2019.

CNPq; CAPES. Ciência sem Fronteiras: inscrições e resultados. Brasília, 2016a. Disponível em: http://www.cienciasemfronteiras.gov.br/web/csf/inscricoes-resultados. Acesso em: 20 set. 2019. 
CNPq; CAPES. Painel de controle do Programa Ciência sem Fronteiras. Brasília, 2016b. Disponível em: http://www.cienciasemfronteiras.gov.br/web/csf/painel-de-controle. Acesso em: 8 set. 2019.

CNPq; CAPES. Ciência sem Fronteiras: um programa especial de mobilidade internacional em ciência, tecnologia e inovação. Brasília, 2011.

CONTEL, Fábio Betioli; LIMA, Manolita Correia. A internacionalização da educação superior nos EUA: principais características. Revista Eletrônica de Negócios Internacionais, São Paulo, v. 3, n. 2, p. 162-80, ago./dez. 2008.

CONTEL, Fabio Betioli; LIMA, Manolita Correia. Aspectos da internacionalização do ensino superior: origem e destino dos estudantes estrangeiros no mundo atual. Revista Eletrônica de Negócios Internacionais da ESPM, São Paulo, v. 2, n. 2, p. 167-193, jul./dez. 2007.

IANNI, Octávio. O cidadão do mundo. In: LOMBARDI, José Claudinei; SAVIANI, Dermeval; SANFELICE, José Luís (Org.). Capitalismo, trabalho e educação. 2. ed. rev. Campinas, SP: Autores Associados, 2004. p. 27-34.

MELLO, Alex Fiúza de. Marx e a globalização. São Paulo: Boitempo, 1999.

PINTO, Marialva Moog; LARRECHEA, Enrique Martínez. Internacionalização da educação superior: uma análise das tendências de mobilidade dos estudantes entre países do norte e do sul global. Avaliação (Campinas), Sorocaba, SP, v. 23, n. 3, p. 718-35, set./dez. 2018.

RODRÍGUEZ, Margarita Victoria; BRITO, Silvia Helena Andrade de; PAIVA, Flávia Melville. O processo de internacionalização na/da Universidade Federal de Mato Grosso do Sul (UFMS) - Brasil. Revista Internacional de Educação Superior, Campinas, SP, v. 5, p. 1-28, 2019. Disponível em: https://periodicos.sbu.unicamp.br/ojs/index.php/riesup/article/ view/8653819/19207 . Acesso em: 20 abr. 2019.

SILVA CARVALHO, Claudiane. Programa Ciência sem Fronteiras na UFV, Campus de Rio Paraíba: êxitos e fracassos. 2015. 147f. Dissertação (Mestrado Profissional em Gestão e Avaliação da Educação Pública) - Universidade Federal de Viçosa, Viçosa, MG, 2015.

SILVA JUNIOR, João dos Reis da; KATO, Fabíola Bouth Grello. A política de internacionalização da educação superior no plano nacional de pós-graduação (2011-2020). Revista Internacional de Educação Superior, Campinas, SP, v. 2, n. 1, p. 138-51, jan./abr. 2016.

THIENGO, Lara Carlette. Universidades de classe mundial ou o fim da universidade como Universitas? Campinas, SP: Mercado das Letras, 2019. 
UFMS. AGINOVA. Divisão de Relações Internacionais. Mobilidade acadêmica internacional outgoing: graduação e pós-graduação 2016-2018. Campo Grande, MS, 2020.

UFMS. Resolução n. 80, de 30 de agosto de 2018. Estabelece o Plano Institucional de Internacionalização no âmbito da Fundação Universidade Federal de Mato Grosso do Sul. Boletim Oficial da Fundação Universidade Federal de Mato Grosso do Sul, Campo Grande, n. 6868, p. 1-14, 31 ago. 2018. Disponível em: https://boletimoficial.ufms.br/. Acesso em: 8 set. 2019.

UFMS. Relatórios de Gestão: exercícios 2011 a 2017. Campo Grande, MS, 2012-2018.

UFMS. Edital n. 64, de 29 de setembro de 2011. PDSE período 2012. Boletim Oficial da Fundação Universidade Federal de Mato Grosso do Sul, Campo Grande, n. 5147, p. 13, 31 out. 2011. Disponível em: https://boletimoficial.ufms.br/. Acesso em: 8 set. 2019.

UFMS. Histórico. [s.d.]. Disponível em: https://www.ufms.br/universidade/historico/. Acesso em: 20 mar. 2019.

\section{Sobre as autoras:}

Silvia Helena Andrade de Brito: Doutora em Educação pela Universidade Estadual de Campinas (UNICAMP). Professora e pesquisadora sênior da Universidade Federal de Mato Grosso do Sul (UFMS), Campus Campo Grande. E-mail: s.helena.brito@uol.com.br, Orcid:http://orcid.org/0000-0002-6186-3980

Margarita Victoria Rodríguez: Doutora em Educação pela Universidade Estadual de Campinas (UNICAMP). Professora Associada da Universidade Federal de Mato Grosso do Sul (UFMS), Campus Campo Grande. E-mail: poroyan@uol.com.br, Orcid: http://orcid.org/0000-0003-3075-9336

Carina Elisabeth Maciel: Doutora em Educação pela Universidade Federal de Mato Grosso do Sul (UFMS). Professora Adjunta da Universidade Federal de Mato Grosso do Sul (UFMS), Campus Campo Grande. E-mail: carina.maciel@ufms.br, Orcid: http://orcid.org/0000-0003-3765-3139

\section{Recebido em 10 de outubro de 2019.}

Aprovado em 18 de fevereiro de 2020. 